\title{
Pentacuspid aortic valve diagnosed by transoesophageal echocardiography
}

\author{
M Cemri, A Cengel, T Timurkaynak
}

\begin{abstract}
Congenital aortic valve anomalies are quite a rare finding in echocardiographic examinations. A case of a 19 year old man with a pentacuspid aortic valve without aortic stenosis and regurgitation, detected by transoesophageal echocardiography, is presented.

(Heart 2000;84:e9)
\end{abstract}

Keywords: pentacuspid aortic valve; echocardiography

Monocuspid, bicuspid or quadricuspid aortic valves are a rare congenital malformation of the aortic valve. ${ }^{1}$ However, to our knowledge there has been no previous report of a pentacuspid aortic valve in the literature. Although transthoracic echocardiography can delineate aortic valve structure, image quality may be suboptimal in some cases. In these cases, transoesophageal echocardiography may be required to clarify the aortic valve structure and function. We report a case of a pentacuspid aortic valve diagnosed by transoesophageal echocardiography.

Gazi University,

Faculty of Medicine, Department of

Cardiology, Ankara, Turkey

M Cemri

A Cengel

$\mathrm{T}$ Timurkaynak

Correspondence to: Dr Mustafa Cemri, Iýk sk. 5/10 Tandodan 06570 Ankara, Turkey mcemri@superonline.com

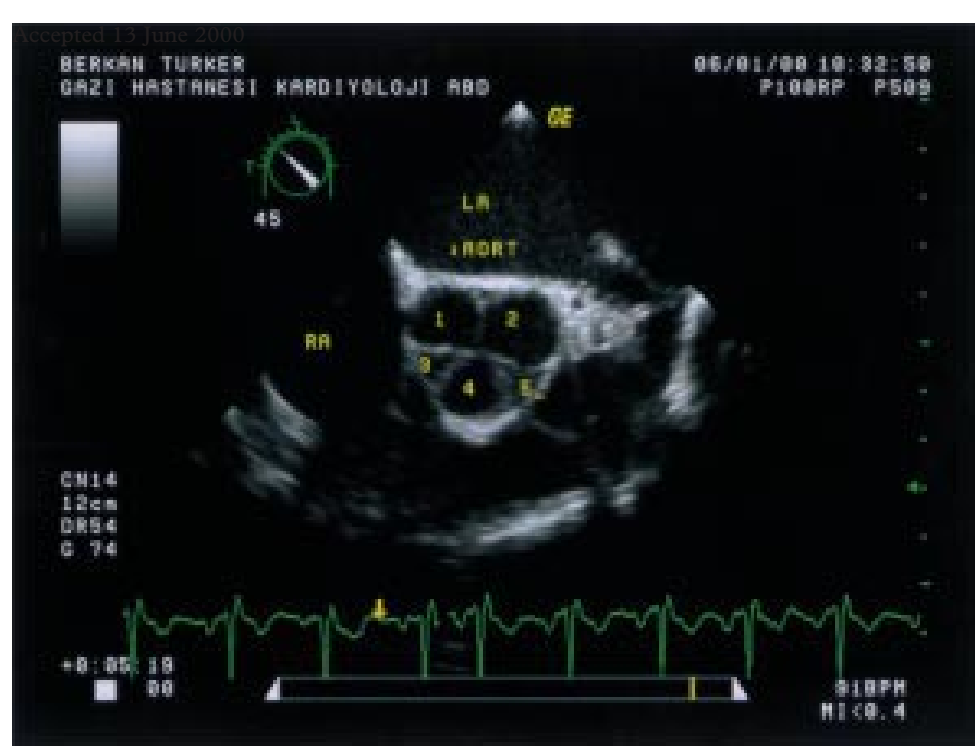

Figure 1 Transoesophageal echocardiographic basal short axis scan at level of the aortic valve. There is a pentacuspid aortic valve with three relatively equal cusps (1,2, and 4) and two smaller cusps ( 3 and 5). mal S1 and S2 without S3 and S4. A grade I-II/VI systolic ejection murmur was heard at the left sternal border. His ECG revealed normal sinus rhythm and his chest $x$ ray was also normal. Additionally, his routine blood and urine analyses were normal. However, transthoracic echocardiography showed mitral valve prolapse and suspicion defect imaging in the interatrial septum. The structure of the interatrial septum and interatrial shunt could not be adequately assessed because of suboptimal imaging quality. A tricuspid aortic valve with normal structure and function was seen. Transoesophageal echocardiography was performed and revealed a patent foramen ovale, mitral valve prolapse with mitral regurgitation (I/IV), and a pentacuspid aortic valve with three relatively equal cusps and two smaller cusps (fig 1). In spite of the different aortic valve structure, no aortic stenosis and regurgitation was seen.

\section{Discussion}

The aortic valve is derived from mesenchymal swellings in the aortic trunk by the fourth week of gestation. ${ }^{2}$ Normally, three outgrowths bulge into the lumen of the great vessel and develop into three semilunar cusps that coapt in the centre of the valve orifice. It has been suggested that an abnormal number of cusps result from developmental changes in the early stages of truncal separation. ${ }^{3}$ Case reports of quadricuspid aortic valve describe patients ranging in age from $30-70$ years. ${ }^{4}$ Aortic stenosis is rare, but approximately $50 \%$ of patients with quadricuspid aortic valve have aortic regurgitation. ${ }^{4}$ Our patient was much younger, and we did not detect aortic stenosis or aortic regurgitation probably because these complications had not had time to develop yet. Initially, we reported a tricuspid aortic valve upon transthoracic echocardiography. Because the two supernumeracy cusps were much smaller, they escaped detection using this imaging technique.

The incidence of quadricuspid aortic valve has been reported at between $0.008 \%$ and $0.033 \%$ in necropsy series. ${ }^{5}$ To our knowledge, this is the first case of a pentacuspid aortic valve diagnosed exclusively by transoesophageal echocardiography reported in the English language literature. Pseudo-pentacuspid aortic valve may be seen secondary to bacterial endocarditis or rheumatic valvulitis. However, both physical and laboratory evaluation found no evidence for endocarditis and rheumatic fever at the time of the patient's admission to our hospital. We think that, in this case, the pentacuspid aortic valve was a rare congenital anomaly. The patient's palpitations could have developed as a result of mitral valve prolapse. 
1 Janssens U, Klues HG, Hanrath P. Congenital quadricuspid aortic valve anomaly associated with hypertrophic nonobstructive cardiomyopathy: a cas
literature. Heart 1997;78:83-7.

2 Gordon S. Quadricuspid aortic valve. Am $f$ Cardiol 1991;67:323-4

3 Davia JE, Fenoglio JJ, DeCastro CM. Quadricuspid semilunar valves. Chest 1977;72:186-9.
4 Barbosa MM, Motta MS. Quadricuspid aortic valve and aortic regurgitation diagnosed by Doppler echocardiography: report of two cases and rewiew of the literature. $\mathcal{F}$ Am Soc Echocardiogr 1991;4:69-74.

5 Hurwitz LE, Roberts WC. Quadricuspid semilunar valve. Am F Cardiol 1973;31:623-6. 